\title{
TEKNIK INJEKSI INTRAMUSKULAR TANPA ASPIRASI UNTUK MENURUNKAN INTENSITAS NYERI SAAT PROSEDUR INJEKSI VITAMIN NEUROBION 5000 PADA PASIEN POLI RAWAT JALAN RUMAH SAKIT ADVENT BANDUNG
}

\author{
INTRAMUSCULAR INJECTION TECHNIQUES WITHOUT ASPIRATION TO REDUCE \\ THE INTENSITY OF THE PAIN WHILE PROCEDURES INNECTION OF VITAMIN \\ NEUROBION 5000 ON PATIENTS PATTERN OF HOSPITAL ROAD ADVENT \\ BANDUNG
}

Corry Laodikia', Evelyn Tambunan ${ }^{2}$

Fakultas Ilmu Keperawatan, Universitas Advent Indonesia

E-Mail: claodikia@gmail.com

\begin{abstract}
ABTRACK
Pendahuluan: Penulisan skripsi ini dilatarbelakangi oleh pengalaman penulis saat bertugas di rumah sakit Advent Bandung, dimana prosedur penyuntikan intramuskular merupakan salah satu tindakan yang menimbulkan nyeri dan menggangu kenyamanan pasien. Prosedur baku yang berlaku hingga saat ini adalah masih menggunakan teknik aspirasi saat melakukan penyuntikkan intramuskular. Tujuan: tujuan penelitian ini adalah untuk memperoleh gambaran intensitas nyeri penyuntikan intramuskular vitamin neurobion 5000 dengan teknik aspirasi dan tanpa aspirasi, serta perbedaan yang signifikan intesitas nyeri antara kedua teknik tersebut. Metode: Metode penelitian adalah metode quasi experimental dengan model non-equivalent control group. Populasi yang digunakan dalam penelitian ini adalah pasien poli rawat jalan rumah sakit Advent dengan jenis kelamin perempuan usia $\geq 18$ tahun. Sampel berjumlah 44 responden yang dipilih secara purposive sampling. Instrumen yang digunakan dalam penelitian ini adalah lembar observasi yang berupa skala nyeri penyuntikan intramuskular vitamin neurobion 5000 yang akan diisi oleh observer. Hasil: Hasil analisa statistik Mann Whitney terdapat perbedaan skala nyeri yang signifikan dengan nilai p $0,001(\square=0,05)$ antara prosedur penyuntikan intramuskular vitamin neurobion 5000 dengan teknik aspirasi dan tanpa aspirasi. Sehingga dapat disimpulkan bahwa teknik injeksi intramuskular tanpa aspirasi efektif dapat menurunkan skala nyeri penyuntikan intramuskular di Rumah Sakit Advent Bandung. Diskusi: diharapkan teknik tanpa aspirasi ini dapat menjadi prosedur baku dalam Standard operational procedure (SOP) yang berlaku, dan bagi penelitian selanjutnya untuk menggunakan jumlah sampel yang lebih banyak dan lebih homogen/spesifik, alat pengukuran skala nyeri yang berbeda dan jenis/larutan obat yang berbeda.
\end{abstract}

Kata kunci: injeksi intramuskular teknik aspirasi, injeksi intramuskular teknik tanpa aspirasi, intensitas nyeri

\begin{abstract}
Introduction: Writing this thesis is motivated by the experience of the author while on duty at Advent Bandung hospital, where intramuscular injection procedure is one of the actions that cause pain and disrupt patient comfort. The standard procedure that is in force today is still using aspiration techniques while performing intramuscular injections. Purpose: The purpose in writing this scientific paper is to obtain a description of the intensity of intramuscular injection of vitamins neurobionics 5000 with aspiration techniques and without aspiration, as well as significant differences in pain intensity between the two techniques. Method: The method used in this study is quasi experimental method with non-equivalent control group model. The population used in this study was the outpatients of Adventist hospital outpatients with female gender aged $\geq 18$ years. The sample was 44 respondents selected by purposive sampling. The instrument used in this study is an observation sheet in the form of intramuscular pain
\end{abstract}

JURNAL

SKOLASTIK KEPERAWATAN

Vol, 3, No. 2 Juli- Desember 2017

ISSN: $2443-0935$ E-ISSN 2443 - 1699 
injection scale of vitamin neurobionics 5000 which will be filled by the observer. Parameters measured in this study were pain intensity with verbal rating scale (VRS) $0-3$. VRS is a valid instrument $(p=0.01)$ and is commonly used in clinical practice to measure pain intensity. Result: Mann Whitney statistical analysis results there are significant differences in pain scale with $p$ value 0.001 ( $\square=0.05$ ) between intramuscular injection procedure of vitamin neurobionics 5000 with aspiration technique and without aspiration. Discussion: So it can be concluded that intramuscular injection technique without effective aspiration can reduce the scale of intramuscular injection pain at Advent Bandung Hospital. Suggestion: It is hoped that this aspiration less technique can become standard procedure in applicable Standard Operational Procedure (SOP), and for subsequent research to use more and more homogeneous sample quantities, different pain scale measurement tools and drug type / solution different.

Keywords: intramuscular injection aspiration technique, intramuscular injection technique without aspiration, pain intensity

\section{PENDAHULUAN}

Pemberian obat melalui lapisan otot disebut intramuskular, dapat menjadi satusatunya rute pemberian obat bila pasien mengalami iritasi saat diberikan secara intravena dan pengganti pemberian oral karena beberapa obat rusak oleh sistem pencernaan (Ford et al 2010). Salah satu komplikasi yang ditimbulkan pada prosedur injeksi intramuskular adalah nyeri oleh adanya trauma jaringan akibat luka tusuk (Malkin. B, 2008). Beberapa penelitian menunjukkan adanya dampak nyeri terhadap kenyamanan pasien. Hasil penelitian Taddio, Ilersich, Ipp, et al (2009) dan Taddio, Mc Murtry, Shah, et al (2015) membuktikan takut datang berobat, pengobatan tertunda, stres pada orangtua bila pasien anak, dalam lainlain merupakan bentuk ketidaknyamanan yang timbul pada pasien yang mendapatkan suntikan intramuskular.

Saat seseorang menerima perawatan di rumah sakit, maka ia akan menuntut mutu pelayanan dari rumah sakit tersebu termasuk pelayanan keperawatan. Dalam hal ini perawat memiliki peranan penting untuk memberikan asuhan keperawatan yang memenuhi kebutuhan pasien secara holistik sehingga tercapai tingkat kepuasan pasien (Resandi et al, 2015). Asuhan keperawatan yang bermutu, berkualitas, aman dan nyaman didasarkan pada pelaksanaan asuhan yang sesuai dengan Standart Operational Procedure (SOP) (Hilmawan, Suprapti, Solechan (2014)). SOP keperawatan merupakan tata laksana tindakan keperawatan, yang bertujuan untuk menyeragamkan langkahlangkah asuhan keperawatan dan meminimalkan terjadinya komplikasi asuhan keperawatan.

Riset keperawatan terus mengembangkan penelitian untuk menemukan berbagai tehnik untuk mengurangi tingkat nyeri pada saat prosedur injeksi intramuskular dilakukan pada pasien. Beberapa teknik dapat dilakukan untuk meminimalkan nyeri yang timbul akibat suntikan intramukular yaitu di antaranya menggunakan sentuhan, kompres dingin, temperatur jarum, tekanan halus dan pijatan (Bartell et al., 2008). Beberapa tehnik injeksi juga dimodifikasi dari standar injeksi tradisional seperti kecepatan penyuntikan, teknik z-track, tehnik air lock, dan tidak melakukan 
aspirasi sebelum mendorong obat ke lapisan jaringan otot (Malkin B (2008), Tambunan (2014), Taddio, Mc Murtry, Shah, et al (2015).

Rekomendasi dari World Health Organization (2015) dalam prosedur injeksi intramuskular untuk semua usia salah satunya adalah tidak melakukan aspirasi. Hal ini bertujuan untuk mengurangi waktu kontak jarum suntik dengan jaringan otot dan tidak memperluas trauma jaringan sehingga nyeri berkurang (WHO, 2015). Terdapat beberapa penelitian yang mendukung rekomendasi WHO tersebut. Hasil penelitian Taddio, Mc Murtry, Shah, et al (2015) dan Hogan, Kikuta, Taddio (2009) menyatakan bahwa tingkat nyeri pada prosedur injeksi intramuskular tanpa aspirasi lebih rendah dibandingkan prosedur penyuntikan intramuskular menggunakan aspirasi dengan kecepatan lambat.

Beberapa informasi yang peneliti dapatkan dari rekan-rekan sejawat masih menggunakan tehnik aspirasi saat injeksi intramuskular. Hal ini juga berkaitan dengan Prosedur Baku yang telah tersedia di Rumah Sakit dimana peneliti bekerja masih menggunakan tehnik aspirasi saat prosedur injeksi intramuscular.

\section{TUJUAN PENELITIAN}

Tujuan umum dari penelitian ini adalah Maksud penelitian adalah untuk membuktikan perbedaan intensitas nyeri saat prosedur injeksi intramuskular vitamin neurobion 5000 dengan dan tanpa aspires

\section{KEGUNAAN PENELITIAN}

1. Hasil penelitian ini diharapkan Pasien sebagai penerima layanan kesehatan yaitu mendapatkan layanan kesehatan yang aman dan nyaman.

2. Direktur Keperawatan sebagai informasi untuk meningkatkan layanan keperawatan yang aman dan nyaman.

3. Perawat sebagai tenaga pelaksana untuk memberikan tindakan keperawatan yang aman dan nyaman demi meningkatkan kualitas layanan keperawatan yang berpedoman pada standart operational procedure (SOP) yang telah diperbarui.

4. Bidang penelitian sebagai bahan yang dikembangkan pada penelitian selanjutnya dengan menggunakan jumlah sampel yang lebih banyak

\section{BAHAN DAN METODE}

Metode penelitian yang digunakan dalam penelitian ini adalah metode quasi experimental dengan model nonequivalent control group. Menurut Hidayat,A (2012) pada model nonequivalent control group kelompok eksperimental dan kelompok kontrol dibandingkan, dimana pemilihan masingmasing kelompok tidak dilakukan secara random.

Sampel yang digunakan pada penelitian ini adalah 44 pasien poli rawat jalan yang mendapat order dokter penyuntikan intramuscular vitamin neurobion 5000 di rumah sakit Advent Bandung. Sampel terbagi menjadi dua kelompok yaitu 22 pasien kelompok penerima tindakan penyuntikan dengan teknik aspirasi dan 22 pasien kelompok penerima tindakan penyuntikan dengan teknik tanpa aspirasi,

107 | Jurnal Skolastik Keperawatan | Vol.3, No.2 | Jul - Des 2017 
yang dipilih dengan menggunakan teknik purposive sampling. Menyatakan purposive sampling adalah teknik penarikan yang diambil berdasarkan pada pertimbangan tertentu dari penelitian dengan alasan dan tujuan tertentu (Sugiyono, 2014).

Kriteria pemilihan sampel pada penelitian ini, berupa: pasien poli rawat jalan; jenis kelamin wanita; berusia $\geq 18$ tahun; merupakan pasien dengan pengalaman $\leq 5$ kali menerima prosedur penyuntikan intramuskular; pasien yang mendapat order dokter untuk penyuntikan neurobion 5000 injeksi intramuskular; pasien yang mau ikut serta dalam penelitian setelah mendapatkan informasi yang jelas mengenai tujuan dan manfaat penelitian, dan telah menandatangani informed consent. Instrumen yang digunakan dalam penelitian ini adalah lembar observasi berupa skala nyeri penyuntikan intramuskular vitamin neurobion 5000 yang akan diisi oleh observer. Parameter yang diukur pada penelitian ini adalah intensitas nyeri dengan skala penilaian verbal (VRS) $0-3$. Kategori 0: tidak nyeri (menyatakan tidak nyeri), 1 adalah nyeri ringan (menyatakan nyeri tanpa perubahan perilaku nyeri), 2 adalah nyeri sedang (menyatakan nyeri tanpa ditanya dan dibarengi perubahan perilaku seperti wajah tegang), 3 adalah nyeri berat (menyatakan nyeri dengan keras wajah meringis, berteriak, mengeluarkan air mata, tangan tidak mau dipegang).

Adapun prosedur yang dilakukan dalam proses pengumpulan adalah sebagai berikut :

1. Pada tanggal 16 Maret 2017 peneliti akan meminta izin tertulis kepada Dekan Fakultas Ilmu Keperawatan
UNAI untuk melakukan penelitian di Rumah Sakit Advent Bandung.

2. Pada tanggal 17 Maret 2017 peneliti akan meminta izin tertulis dari Diklat, Direktur Rumah Sakit dan Direktur Keperawatan Rumah Sakit Advent Bandung.

3. Setelah izin didapatkan, pada tanggal 31 Maret 2017 peneliti menemui kepala Instalasi Rawat Jalan Rumah Sakit Advent Bandung, setelah itu peneliti memperkenalkan diri, menjelaskan tujuan dan kegunaan penelitian, serta etika pengumpulan data.

4. Pelaksanaan prosedur injeksi dilakukan setelah mendapat persetujuan dari setiap sampel, yaitu 44 pasien dari poli rawat jalan yang mendapat order dokter untuk penyuntikan neurobion 5000 injeksi intramuskular. Kemudian peneliti menjelaskan kepada subjek tentang tujuan, efek intervensi, dan perlindungan akan kerahasiaan subjek penelitian. Kemudian peneliti meminta subjek untuk bersedia menandatangani informed consent sebagai bukti bahwa subjek bersedia untuk berpartisipasi dalam penelitian ini. Pada saat prosedur injeksi intramuskular dilakukan menggunakan tehnik aspirasi kepada 22 pasien dan tanpa aspirasi kepada 22 pasien, maka data intensitas nyeri yang diukur menggunakan skala penilaian verbal (Verbal Rating Scale/VRS) didapatkan untuk selanjutnya diolah untuk mendapatkan hasil penelitian. Jenis larutan yang disuntikkan adalah vitamin neurobion 5000 sebanyak $2 \mathrm{cc}$, dengan jarum ukuran $23 \mathrm{G}$ x 1 1/4" dan lokasi penyuntikan adalah daerah ventro gluteal. Pada saat peneliti melakukan prosedur penyuntikan, 
maka asisten peneliti yang berjumlah satu orang akan mengukur intensitas nyeri menggunakan skala penilaian verbal (Verbal Rating Scale/VRS) tanpa mengetahui teknik penyuntikan yang digunakan oleh peneliti.

\section{HASIL PENELITIAN}

Hasil penelitian diperoleh melalui metode quasi experimental dengan model non-equivalent control group dari 44 pasien poli rawat jalan Rumah Sakit Advent Bandung. Responden terbagi menjasi dua kelompok yaitu: 22 pasien kelompok penerima tindakan penyuntikan dengan teknik aspirasi dan 22 pasien kelompok penerima tindakan penyuntikan dengan teknik tanpa aspirasi yang mendapat order dokter untuk penyuntikan intramuskular vitamin neurobion 5000. Data yang dikumpulkan diolah untuk menjawab identifikasi masalah pertama sampai ketiga.

\section{Intensitas Nyeri Saat Prosedur Injeksi Intramuskular Vitamin Neurobion 5000 Dengan Menggunakan Tehnik Aspirasi.}

Untuk menjawab identifikasi masalah pertama, yaitu: "Bagaimanakah intensitas nyeri saat prosedur injeksi intramuskular vitamin neurobion 5000 dengan menggunakan tehnik aspirasi?", maka diukur skala nyeri penyuntikan pasien yang dilakukan oleh observer dan telah didokumentasikan ke dalam lembar observasi. Kemudian hasil penghitungan rata-rata dan standart deviasi berdasarkan pengolahan pada program SPSS dapat dilihat dari tabel 1.

Tabel 1. Rata-Rata Intensitas Nyeri Saat Prosedur Injeksi Intramuskular Vitamin
Neurobion 5000 Dengan Menggunakan Tekhnik Aspirasi.

\begin{tabular}{|c|c|c|c|c|}
\hline $\begin{array}{l}\text { Intensita } \\
\text { s nyeri }\end{array}$ & $n$ & $\begin{array}{l}\text { Mea } \\
\mathrm{n}\end{array}$ & SD & $\begin{array}{l}\text { Interpretas } \\
\text { i }\end{array}$ \\
\hline Teknik & 2 & 1,86 & ,64 & Nyeri \\
\hline Aspirasi & 2 & & 0 & Ringan \\
\hline
\end{tabular}

Tabel 1. menunjukkan bahwa hasil ratarata pengukuran skala nyeri penyuntikan intramuskular vitamin neurobion 5000 dengan teknik aspirasi adalah 1,86 dengan standar deviasi 0,640 termasuk dalam kategori nyeri ringan.

\section{Intensitas Nyeri Saat Prosedur Injeksi Intramuskular Vitamin Neurobion 5000 Dengan Menggunakan Tehnik Tanpa Aspirasi.}

Untuk menjawab identifikasi masalah kedua, yaitu:"Bagaimanakah intensitas nyeri saat prosedur injeksi intramuskular vitamin neurobion 5000 tanpa menggunakan tehnik aspirasi?", maka dilakukan cara yang sama

dengan identifikasi masalah yang pertama. Hasil penghitungan rata-rata dan standar deviasi berdasarkan pengolahan pada program SPSS dapat dilihat dari tabel 2.

Tabel 2. Rata-Rata Intensitas Nyeri Saat Prosedur Injeksi Intramuskular Vitamin Neurobion 5000 Dengan Menggunakan Tehnik Tanpa Aspirasi.

\begin{tabular}{lllll}
\hline $\begin{array}{llll}\text { Intensita } \\
\text { s nyeri }\end{array}$ & $\mathrm{n}$ & $\begin{array}{l}\text { Mea } \\
\mathrm{n}\end{array}$ & $\mathrm{SD}$ & $\begin{array}{l}\text { Interpretas } \\
\mathrm{i}\end{array}$ \\
\hline Teknik & 2 & 1,42 &, 75 & Nyeri \\
Aspirasi & 2 & & 0 & Ringan \\
\hline
\end{tabular}


Tabel 2 menunjukkan bahwa hasil ratarata pengukuran skala nyeri penyuntikan intramuskular vitamin neurobion 5000 dengan teknik tanpa aspirasi adalah 1,42 dengan standar deviasi 0,750 termasuk dalam kategori nyeri ringan.

\section{Perbedaan Intensitas Nyeri Antara Penggunaan Tehnik Aspirasi dan Tanpa Aspirasi Pada Prosedur Injeksi Intramuskular Neurobion 5000.}

Untuk menjawab identifikasi masalah ketiga, yaitu: “Apakah terdapat perbedaan intensitas nyeri yang signifikan antara penggunaan tehnik aspirasi dan tanpa aspirasi pada

prosedur injeksi intramuskular neurobion 5000?', maka dilakukan uji hipotesa dua sampel independen. Berdasarkan analisa statistik didapati bahwa data responden penelitian tidak berdistribusi normal, oleh karena itu peneliti menggunakan analisa statistik Mann Whitney yang dapat dilihat pada tabel 3.

Tabel 3. Perbedaan Intensitas Nyeri Yang Signifikan Antara Penggunaan Tehnik Aspirasi dan Tanpa Aspirasi Pada Prosedur Injeksi Intramuskular Neurobion 5000

Rank

\begin{tabular}{llll}
\hline Sampel & $N$ & $\begin{array}{l}\text { Mean } \\
\text { Rank }\end{array}$ & $\begin{array}{l}\text { Sum Of } \\
\text { Rank }\end{array}$ \\
\hline Aspirasi & 22 & 28.52 & 627.50 \\
Rasa & 22 & 16.48 & 362.50 \\
nyeri & & & \\
non & & \\
aspirasi & & \\
Total 44 & & \\
Test Statistic & & \\
\hline
\end{tabular}

\begin{tabular}{|c|c|c|}
\hline & & Rasa Nyeri \\
\hline MannWhitney & & 109.500 \\
\hline Wilcoxon W & & 362.500 \\
\hline Z & & -3.352 \\
\hline $\begin{array}{l}\text { Asymp } \\
\text { (2tailed) }\end{array}$ & Sig. & .001 \\
\hline
\end{tabular}

Tabel 3. menunjukkan bahwa terdapat 22 responden penerima prosedur injeksi intramuskular vitamin neurobion 5000 dengan teknik aspirasi dan 22 responden penerima prosedur injeksi intramuskular vitamin neurobion 5000 dengan teknik tanpa aspirasi dengan analisa statistik Mann Whitney memiliki perbedaan skala nyeri yang signifikan dengan nilai $\mathrm{p} 0,001$ $(\square<0,05)$.

Pengujian hipotesis juga dapat dilakukan dengan membandingkan nilai $p$ (probabilitas) dengan taraf nyata $(\square)$ dengan ketentuan jika $\mathrm{p}>\square$ maka $\mathrm{H}_{0}$ diterima, jika $\mathrm{p} \leq \square$ maka $\mathrm{H}_{0}$ ditolak. Berdasarkan teori tersebut maka $\mathrm{H}_{0}$ ditolak dengan nilai p $0,001(\square<0,05)$.

Hasil penelitian ini sependapat dengan hasil penelitian yang dilakukan oleh Hogan, Kikuta, Taddio (2009) yang menyatakan bahwa teknik injeksi intramuskular tanpa aspirasi dapat mengurangi nyeri penyuntikan.

\section{KESIMPULAN}

Dapat disimpulkan bahwa teknik injeksi intramuskular tanpa aspirasi efektif dapat menurunkan skala nyeri penyuntikan intramuskular di Rumah Sakit Advent Bandung. Peneliti merekomendasikan agar perawat dapat meningkatkan mutu pelayanan asuhan keperawatan dengan menerapkan dan menggunakan teknik 
tanpa aspirasi saat memberikan terapi obat secara intramuskular.

Peneliti merekomendasikan agar Rumah Sakit Advent Bandung dapat memasukkan teknik tanpa aspirasi saat prosedur penyuntikan intramuskular pada Standar Operasional Prosedur (SOP),

sehingga dapat meningkatkan kenyamanan pasien saat menerima prosedur penyuntikan tersebut. Diharapkan penelitian ini dapat digunakan sebagai data dasar untuk mengembangkan penelitian berikutnya tentang intensitas nyeri pada penyuntikan intramuskular dengan teknik aspirasi dan tanpa aspirasi menggunakan jumlah sampel yang lebih banyak dan lebih homogen/spesifik, alat pengukuran skala nyeri yang berbeda dan jenis/larutan obat yang berbeda.

\section{DAFTAR PUSTAKA}

American Medical Association. 2010. Module pain management pathophysiology of pain and pain assessment. Available from: www.ama.com. [22 Februari 2017]

Bartell J C, et al. 2008. Needle Temperature Effect on Pain Ratings After Injection. Volume 24, Issue 3, Page 260-264

Bartley, N. 2015. Guidelines on the Administration of Intramuscular and SubCutaneous Injections. Nurxe Practice Comitte

Dalami E. 2015. Etika keperawatan. Jakarta: Trans Info Media

Greenway K. 2014. Rituals in nursing: intramuscular injection. Journal of
Clinical Nursing, DOI: 10.1111/jocn. 12627

Ford L., Maddox C., Moore E. and Sales R. 2010. The safe management of medicines for children. In Practices in Children's Nursing: Guidelines for Community and Hospital. 3rd edn, (Trigg E and Mohammed TA., Eds), Churchill Livingstone, Edinburgh, 417 -445.

Hetingger D, Jurkovich P. n.d. Evidencebased Injection Practice: To Aspirate or Not. Sanford Medical Center

Hidayat A. 2007. Metode penelitian keperawatan dan teknik analisis data. Jakarta: Salemba Medika

Hilmawan F A, Suprapti E, Solechan A. 2014. Hubungan antara penerapan standart operational procedure (sop) pemberian obat prinsip enam benar dengan tingkat kepuasan pasien di rsud ungaran. Karya Ilmiah S1 Keperawatan. STIKES Telogorejo

Hogan M E, Kikuta A, Taddio A. (2009). A systematic review of measures for reducing injection pain during adult immunization. Vaccine 28. Elsevier

Hunter, J. 2008. Intramuscular injection techniques. Nursing Standard; 22: $24,35-40$

Kozier, B et al. 2010. Buku ajar fundamental keperawatan; konsep, proses dan praktik. Edisi 7, Volume 2, Cetakan 2011. Jakarta: EGC 
Malkin, B. 2008. Are techniques used for intramuscular injection based on research evidence? Nursing Times; 104: 50/51, pp 48-51

McCaffery, M., Boebe,A; et al. 1989. Pain: Clinical Manual for Nursing Practice. Mosby St.Lois, Mo.

Nicoll LH \& Hesby A. 2002. Intramuscular injection: An integrative research review and guideline for evidencebased practice. Nursing Research Volume 15, Issue 3, Page 149-162. Elsevier

Nursalam. 2008. Konsep dan penerapan metodologi penelitian ilmu keperawatan. Jakarta: Salemba Medika

Potter \& Perry.2005. Fundamental Of Nursing, Proses Konsep dan Praktis. Edisi 4 Volume 2. Jakarta.

Resandi, Muhamad and SUHARNOMO, Suharnomo and Rahardjo, Mudji. 2015. Analisis pengaruh beban kerja perawat terhadap kepuasan pasien dengan kepuasan kerja perawat dan perilaku caring sebagai variabel intervening (studi pada rumah sakit islam sultan agung semarang). Master's thesis, Diponegoro University

Rosady F, Pradian E, Surahman E. 2014. Perbandingan visual analog score antara teknik injeksi air steril intrakutan satu titik dan empat titik untuk mengurangi nyeri persalinan spontan. Jurnal Anestesi Perioperatif. Fakultas Kedokteran
Universitas Padjajaran/Rumah Sakit Dr. Hasan Sadikin Bandung

Santoso S, Hidayat. (2014). Statistik nonparametrik. Jakarta: Elex Media Komputindo

Smeltzer SC, Bare BG. 2008. Brunner and Suddarth's Textbook of Medical Surgical Nursing. 10th edition. Philadelphia: Lippincott Williams \& Wilkins Standard Operational Procedure. 2009. Rumah Sakit Advent Bandung

Sugiyono. 2010. Statistika untuk Penelitian. Bandung: Alfabeta

Taddio A, Ilersich Al, Ipp M, et al. 2009. Physical Interventions and Injection Techniques for Reducing Injection Pain During Routine Childhood Immunizations: Systematic Review of Randomized Controlled Trials and Quasi Randomized Controlled Trials. Clinical Therapeutics/Volume 31, Supplement B. Elsevier

Taddio A, MC Murtry M, Shah V, et al. 2015. Reducing pain during vaccine injections: clinical practice guideline. CMAJ Guidelines

Tambunan EH, Wulandari IS. 2014. Penggunaan tehnik z-track dan airlock untuk menurunkan rasa nyeri pada tehnik menyuntik intramuskular. Bandung: Prosiding Seminar Nasional Penelitian dan PKM Sains, Teknologi dan Kesehatan 
Uma Sekaran. 2006. Metode Penelitian Bisnis. Jakarta: Salemba Empat

Welchek CM, Mastrangelo L, Sinatra RS, Martinez R. 2009. Qualitative and quantitative assessment of pain. In: Sinatra RS, Casasola OA, Ginsberg B, Vincusi ER, McQuay $\mathrm{H}$, editors. Acute pain management. New York: Cambridge University Press; p.147-68

WHO Report. 2015. Reducingpain at the time of vaccination: WHO position paper, September 2015-
Recommendations. Vaccine 34. Elsevier

Wijaya A T. 2015. Neurobion. Diakses dari:http://www.kerjanya.net/faq/1 1115-neurobion.html [3 Maret 2017]

Wynaden D, Landsborough I, McGowan $S$, Baigmohamad Z, Finn $M$, Pennebaker D. 2006. Best practice guidelines for the adminstration of intramuscular injections in the mental health setting. International Journal of Mental Health Nursing Vol 15 No 3 hlm 195-200 